\title{
Study on Mediating Effects Under Actions of Households' Online Shopping Influence Factors and Cash-free Payment
}

\author{
Ruobing Qin ${ }^{1}$, Jingwen Tan ${ }^{2, *}$ \\ ${ }^{1}$ Eurasia International School, Henan University, 475000 Kaifeng, China \\ ${ }^{2}$ School of Economics, Henan University, 475000, Kaifeng, China
}

\begin{abstract}
Household's online consumption behaviors are affected by multi-dimensional factors. In this work, upon the financial survey data of Chinese family in 2017, households'online shopping influence factors are analyzed in the empirical form, and the mediating effects of cash-free payment on households'decision for online shopping is measured. According to the results therefrom, non-cash payment has certain mediating effect in the process that households'characteristic factors affect the online shopping. Households in cities and involving in higher consumption level for life and clothes have a higher willingness for online shopping. Payment by credit has a positive effect on households'decision for online consumption. Enlarging the noncash payment scale and promote the network infrastructure in villages and towns; reducing the use cost of network in villages and towns, deeply tap the consumption potentials in urban areas; promoting the payment by credit can enlarge the scale of network consumption groups and improve their expenditure willingness.
\end{abstract}

\section{Introduction}

Continuous information revolution pushes digital technology to be applied more extensively, the rapid development of online shopping on its basis is affecting the shopping habits and styles of people deeply. With the severe impact of COVID-19, the world economy and international trade are being contracted and limited. However, offline market contraction, on the contrary, pushes the development of e-business, makes online shopping market keep rapid and steady growth trend, and thereby stimulate vigorously the consumption potentials of people. Whilst stimulating domestic demand and smoothing industry chain and supply chain, the e-business is playing an important role. In recent years, China's ecommerce market has grown rapidly, with online retail sales reaching CNY9006.5 billion in 2018, a year-on-year growth of $23.9 \%$ [1]. By June 2020, there were 749 million online shoppers in China, they created the network retail sales of CNY5150.1 billion, which rose by $7.3 \%$ [2]. The e-business is playing a vital role in the process of pushing the changeover of new and old dynamics, economic upgrading and industry transformation and upgrading. Pushing the new development form of "Internet +" economic society and exerting the advantages of digital economy significantly are the effective measures of enlarging economic internal cycle and promoting high-quality economic development.

Household is the most basic social setting and the basic unit of economic cooperation and social life in human society[3]. Since durables and daily necessities are usually consumed on the demand unit of household, the conclusions from the study on the influencing factors of online shopping by taking household as a unit are representative to some extent.

\section{Research background}

Different from the traditional retail industry, online shopping is achieved by the Internet in the process that commodity or service is transferred from seller (vendor) to consumer (buyer), including the capital flow, logistics and information flow involved. Currently, there are certain bases for the study on the influencing factors for the online shopping willingness of consumers in the academic circles.

Miyazaki and Fernandez (2001) considered that there was an influence relation among consumers' internet experience level (likes or dislikes) [4], usage of alternative remote buying method (such as telephone or mail order), perceived risk of online shopping, and online buying activity. Li Baokun (2018) [5], by investigating thoroughly rural regions in 17 provinces of China and by adopting the approaches of factor analysis and regression analysis on the microlevel, compared the influencing factors of online payment willingness of rural residents for different commodities and in different regions. Bi Yuanyuan (2019) constructed the research model for influencing factors of buying willingness of $\mathrm{C} 2 \mathrm{C}$ online shopping consumers[6], and concluded that commodity factor, seller factor and platform factor were playing the positive significant influence on online shopping willingness, where perceived usefulness and trust were not playing the mediating effect completely. Hu Gangfa screened out 4 common factors by factor analysis[7], i.e.: 
network access factor, online shopping's contactable factor, perceived risk and logistics factor, and established the evaluation model for influencing degree of residents' network consumption willingness. But in the academic circles nowadays, there are few empirical analyses focusing on measuring online shopping habits by taking household as a unit.

In this work, upon the CHFS (China Household Finance Survey) data 2017 as provided by Southwestern University of Finance and Economics, we analyzed the influencing factors of households' online shopping, measured the mediating effect of households' decision for online shopping under the influence of non-cash payment, and analyzed empirically the influencing factors of online shopping behaviors on the unit of household.

\section{Research design}

\subsection{Data source}

CHFS 2017 data provided by Southwestern University of Finance and Economics, as adopted in this work, used 3stage layers and the sampling methods such as popularization size proportion, helped us to comprehensively acquire the microeconomics data of different types of households. The data sample 2017 included the information related to assets and debts of more than 40,000 households in 355 counties and districts in 29 provinces in China, they provided the data basis for our empirical study herein[8]. On the data processing, those samples with the control variables missing values were removed from our study, so the final sample sizes were 31,306 households.

\subsection{Variable selection}

In this work, the explained variable is the one whether the investigated household has experience in online shopping. If the household has the online shopping behavior, the value will be 1 , if not, the value will be 0 .

Based on the analysis of existing literature, we screened out the explained variables from 5 dimensions, i.e.: residence conditions, network application, non-cash payment, credit consumption, expenditure level. For the residence conditions, we selected three variables, i.e.: housing location, house ownership, the quantity of household real estate. For the network application, we selected four variables, i.e.: whether the cell phone is smart, quantity of household cell phone, usage of internet, internet equipment preference. For the non-cash payment, we selected three variables, i.e.: online payment experience, attitude and amount. For the credit consumption dimension, we selected two variables, i.e.: whether the credit card is used, and whether the installment payment is used. For the expenditure level, we selected four variables, i.e.: expenditure for clothes, expenditure for daily necessities, expenditure for recreation, expenditure for food. As for the values of variables, see Table 1 as follows.

\section{Research results and analysis}

\subsection{Binary Logit model}

\subsubsection{Model introduction}

Binary Logit model is one of the discrete selection method models, it belongs to the analysis scope of multiple variables. There are two kinds of values for online shopping experience in the CHFS questionnaire, i.e.: yes $(\mathrm{Y}=1)$ and no $(\mathrm{Y}=0)$, so the binary Logit model is more suitable for our analysis. If the investigated household has the online shopping experience, we defined it as the Event $\mathrm{X}$; assuming the event occurrence probability is $\mathrm{P}, \beta_{i}$ is the regression coefficient of influencing factor, $K$ is the question number, the dependent variable affecting the occurrence of event is defined as $P(x)$ [9-11]. Assuming the function form is linear, the model can be expressed as:

$$
\ln \left(\frac{P(x)}{1-P(x)}\right)=\beta_{0}+\sum_{i=1}^{k} \beta_{i} X_{i}
$$

we can deduce the expression form of Logit model as:

$$
P(x)=\frac{\beta_{0}+\sum_{i=1}^{k} \beta_{i} X_{i}}{1+\exp \left(\beta_{0} \sum_{i=1}^{k} \beta_{i} X_{i}\right)}
$$

Table1. .Variable assignment table

\begin{tabular}{cc}
\hline Variable name & Code \\
\hline Housing location & X1 \\
House ownership & X2 \\
Quantity of household real estate & X3 \\
Whether the cell phone is smart & X4 \\
Quantity of household cell phone & X5 \\
Usage of internet & X6 \\
Internet equipment preference & X7 \\
Online payment experience & X8 \\
Online payment attitude & X9 \\
Online payment amount & X10 \\
Whether the credit card is used & X11 \\
Whether the installment payment is used & X12 \\
Expenditure for clothes & X13 \\
Expenditure for daily necessities & X14 \\
Expenditure for recreation & X15 \\
Expenditure for food & X16 \\
\hline
\end{tabular}

\subsubsection{Model Test}

In the likelihood-ratio test, the value $\mathrm{p}$ is less than 0.05 (see Table 2), signifying the independent variable in the current model is effective, the modeling has its significance. If judging the model fitting quality by the model prediction accuracy, the whole prediction accuracy of model is $86.99 \%$; so the model fitting is acceptable. When the true value is 0 , the prediction accuracy is $93.15 \%$; when the true value is 1 , the prediction accuracy is $76.88 \%$. 
Table2. Model Summary

\begin{tabular}{ccccc}
\hline & $\mathbf{- 2}$ Log likelihood & Chi-square & Df & p \\
\hline Intercept & 41530.796 & & & \\
Model & 19407.352 & 22123.444 & 16 & 0 \\
\hline
\end{tabular}

\subsubsection{Analysis of Results}

In the result of binary Logit model, the P test results of 13 variables reached the significant level of 0.05 , they can cause significant impact on the online shopping experience of investigated household.

On the aspect of region, housing location (X1) and house ownership (X2) have significant impact on the online shopping experience of investigated household. There are complete infrastructures for logistics and network in the regions with developed economy, so the online shopping willingness of households in these regions is rather higher. The regression coefficient of house ownership is negative, certifying the online shopping willingness of house renter group is higher relative to the group having immobilized house. Most of house renter groups are the households working in cities, relative to the households having immobilized houses in towns, they have higher consuming ability and their consumption potential is non-negligible.

On the aspect of equipment, cell phone (X5) and internet access (X6) have significant impact on the online shopping experience of investigated household. The quantity of cell phone in a family can reveal the economic income and internet involvement level of the family, the more the quantity of cell phone in a family is, the richer the family experience in online shopping is, so reducing the internet access cost and the price of mobile network equipment can effectively enlarge the group of online shopper.

On the aspect of online payment, online payment experience (X8), attitude (X9) and amount (X10) have significant positive impact on the household's online shopping experience. Online payment is closely correlated with online shopping. In the following part, we shall analyze the mediating effects between online payment and household's online shopping experience.

Usage of credit card (X11) and consuming habit by installment (X12) have significant impact on the online shopping experience of household. The household having the habit of making payment by credit card or by installment has richer experience in online shopping. The credit card, as it comes out on the market, further simplifies the payment procedures and provides the convenient conditions for online shopping. The household having the habit of making payment for consumption by installment has higher expenditure willingness, which further impacts their decisions for online shopping.

CHFS questionnaire did not involve in the income variables related to household income; we adopted expenditure for clothes (X13), expenditure for daily necessities (X14), expenditure for recreation (X15), expenditure for food (X16) to measure the consumption level of a household. The higher the household expenditure is, the richer experience in online shopping is.
Where: the advantage in the expenditure for clothes is higher, it signifies the household expending more for clothes prefers more to online shopping.

Table3. Variables in the Equation

\begin{tabular}{cccccc}
\hline variable & $\begin{array}{c}\text { Regression } \\
\text { coefficient }\end{array}$ & $\mathbf{Z}$ & Wald & $\mathbf{P}$ & OR \\
\hline $\mathrm{XI}$ & 0.039 & 3.992 & 15.937 & $0.000^{* *}$ & 1.040 \\
$\mathrm{X} 2$ & -0.158 & -2.645 & 6.995 & $0.008^{* *}$ & 0.854 \\
$\mathrm{X} 3$ & 0.010 & 0.281 & 0.079 & 0.779 & 1.010 \\
$\mathrm{X} 4$ & -0.062 & -1.279 & 1.637 & 0.201 & 0.940 \\
$\mathrm{X} 5$ & 0.539 & 29.433 & 866.292 & $0.000^{* *}$ & 1.714 \\
$\mathrm{X} 6$ & 0.879 & 19.336 & 373.866 & $0.000^{* *}$ & 2.410 \\
$\mathrm{X} 7$ & -0.000 & -1.309 & 1.714 & 0.191 & 1.000 \\
$\mathrm{X} 8$ & 1.304 & 14.010 & 196.286 & $0.000^{* *}$ & 3.683 \\
$\mathrm{X} 9$ & 0.235 & 9.668 & 93.461 & $0.000^{* *}$ & 1.265 \\
$\mathrm{X} 10$ & 0.114 & 7.031 & 49.431 & $0.000^{* *}$ & 1.121 \\
$\mathrm{X} 11$ & 0.589 & 10.515 & 110.570 & $0.000^{* *}$ & 1.802 \\
$\mathrm{X} 12$ & 0.311 & 2.467 & 6.088 & $0.014 *$ & 1.365 \\
$\mathrm{X} 13$ & 0.152 & 14.823 & 219.708 & $0.000^{* *}$ & 1.165 \\
$\mathrm{X} 14$ & 0.088 & 5.337 & 28.479 & $0.000^{* *}$ & 1.092 \\
$\mathrm{X} 15$ & 0.109 & 11.559 & 133.610 & $0.000^{* *}$ & 1.115 \\
$\mathrm{X} 16$ & 0.111 & 4.677 & 21.873 & $0.000^{* *}$ & 1.117 \\
\hline & & & & $\mathrm{p}<0.05 * *$ & $\mathrm{p}<0.01$
\end{tabular}

\subsection{Mediating effects}

\subsubsection{Measurement model test}

Before measuring the mediating effects, we firstly conducted the applicability test on data, adopted the principal component analysis to extract common factors, conducted the standardized data processing, and then did the mediating effect analysis. By the principal component analysis, we obtained the results as shown in Tables 4 .

Table4. Rotated Component Matrix

\begin{tabular}{cccccc}
\hline variable & \multicolumn{5}{c}{ component } \\
& $\mathbf{1}$ & $\mathbf{2}$ & $\mathbf{3}$ & $\mathbf{4}$ & $\mathbf{5}$ \\
\hline X8 & .878 & & & & \\
X9 & .800 & & & & \\
X10 & .868 & & & \\
X6 & .586 & .519 & & \\
X1 & & -.523 & & & \\
X4 & & .639 & & & \\
X5 & & .607 & & & \\
X13 & & .614 & & & \\
X14 & & .752 & & & \\
X15 & & .619 & & & \\
X16 & & .664 & & & \\
X2 & & & .842 & & \\
X3 & & & .790 & & \\
X11 & & & & .624 & \\
X12 & & & & & \\
X7 & & & & \\
\hline
\end{tabular}

After reducing dimensionality of principal component for all variables, we conducted the applicability test, and obtained the KMO test value of 0.873 and the Bartlett sphericity significance probability of 0.000 , signifying the data variable complies with the feasibility standard of principal component analysis. For 5 principal components as extracted and shown in Table 5, their cumulative variance contribution rate is $65.455 \%$, signifying the principal component to be extracted can explain the 
original data. According to the test results as shown in Table 4 the variable X6 is the invalid variable; however there is only one variable (X7) in the 5th principal component, it is not highly representative, so it is neglected in the mediating analysis. The other four principal components are the mobile payment component, expenditure component, residence component and credit component.

\subsubsection{Mediating Effects Analysis}

In order to investigate the mediating effects of mobile payment in the acting process of household's online shopping habits, we adopted the test method to measure expenditure index, real estate index and credit index, and then conducted the standardized processing for all variables, where the regression coefficients therefrom are significant, signifying that mobile payment has certain mediating effects in the process of acting household's online shopping habits. The mediating effects of three mediating paths, namely expenditure component, residence component and credit component, share the percentage of total effect as $42.769 \%, 73.116 \%$ and $69.984 \%$ respectively. The popularization of mobile payment can effectively promote the development of ebusiness.

Table5. Summary of mediating effect

\begin{tabular}{|c|c|c|c|}
\hline Model & $\begin{array}{l}\text { Total } \\
\text { effect }\end{array}$ & $\begin{array}{c}\text { medium } \\
\text { effect }\end{array}$ & $\begin{array}{l}\text { direct } \\
\text { effect }\end{array}$ \\
\hline $\begin{array}{l}\text { Expenditure component } \Rightarrow \text { Mobile } \\
\text { payment component }=>\text { Decision }\end{array}$ & $0.207 * *$ & 0.088 & $0.118 * *$ \\
\hline $\begin{array}{l}\text { Residence component }=>\text { Mobile Payment } \\
\text { component } \Rightarrow \text { Decision }\end{array}$ & $0.032 * *$ & 0.023 & $0.009 * *$ \\
\hline $\begin{array}{l}\text { credit component } \Rightarrow>\begin{array}{l}\text { Mobile Payment } \\
\text { component } \Rightarrow>\end{array} \text { Decision }\end{array}$ & $0.398 * *$ & 0.278 & $0.119 * *$ \\
\hline
\end{tabular}

\section{Conclusions and proposals}

According to the studies, those households in economically developed areas and having higher expenditure level have richer experience in online shopping. Usage of credit cards and consuming habit by installment have positive impact on the online shopping experience of household. Those households highly involving in internet applications prefer online shopping. Cash-free payment has a certain mediating effect in the process that households' characteristic factors act on the online shopping of household.

According to the research results, we have three suggestions as follows:

Enlarge online payment scale, promote and innovate non-cash payment tool, promote non-cash payment service environment building. Enhance network infrastructure construction in towns and rural regions, reduce network use cost.

Enhance online shopping platform and system building, improve vendor's reputation level, create healthy and sound online shopping environment, and improve online shopping service quality. Enhance platform monitoring and after-sales services, improve households' willingness for consumption by internet.

Tap consumption potential of cities and towns deeply and enlarge effectively the size of network consumption group. Promote new pattern of online shopping, actuate new types of business on the Internet.

\section{References}

1. China Internet Network Information Center. (2018) Statistical report on Internet development in China.China Internet Network Information Center Press,Beijing.

2. China Internet Network Information Center. (2020) Statistical report on Internet development in China.China Internet Network Information Center Press, Beijing.

3. Zhao,G.(2006)Research on Russian family relationship psychology.Nanjing Normal University, Nanjing.

4. Miyazaki , D . Fernandez, A. (2001) Consumer perceptions of privacy and security risks for online shopping. The Journal of Consumer Affairs, 35: 2754.

5. Li, B. Zhao, B. Liu, Y. Guo, T. (2018) Survey and analysis of rural residents' willingness to pay for online consumption. management world, 34: 4-103.

6. Bi,Y.(2019) Research on the influencing factors of consumer purchase intention of $\mathrm{C} 2 \mathrm{C}$ fresh fruit micro commerce. Yangzhou University, Yangzhou.

7. Hu, G. Zhang,Y. (2017) Research on Influencing Factors of rural residents' online consumption intention based on factor analysis. Journal of Anhui University of science and technology,2:27-32.

8. Southwest University of Finance and economics. (2019) Introduction to China Household Finance Survey database. Economic Research Journal, 54:212.

9. Allison P D.(1999) Logistic Regression Using the SAS System: Theory and Application. Wiley Interscience, America.

10. Peterson,J.(1999) Regression Analysis of Count Data, Technometrics, 41, 1.

11. Wan, C. Luo, J.(2014) Advanced medical statistics. Science Press, Beijing. 